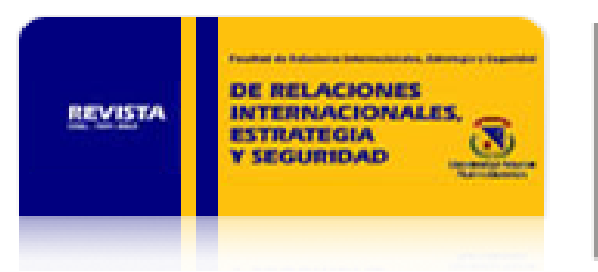

Revista de Relaciones Internacionales, Estrategia y Seguridad

ISSN: 1909-3063

cinuv.relinternal@unimilitar.edu.co

Universidad Militar Nueva Granada

Colombia

Granados-Erazo, Oscar

LA RECONFIGURACIÓN BRASILERA Y EL IMPERIO BRITÁNICO, 1822-1914. ¿DEPENDENCIA O ESTRATEGIA?

Revista de Relaciones Internacionales, Estrategia y Seguridad, vol. 4, núm. 2, julio-diciembre, 2009,

pp. 39-64

Universidad Militar Nueva Granada

Bogotá, Colombia

Disponible en: http://www.redalyc.org/articulo.oa?id=92712972001

- Cómo citar el artículo

- Número completo

- Más información del artículo

- Página de la revista en redalyc.org

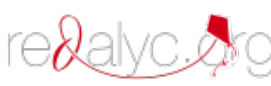

Sistema de Información Científica

Red de Revistas Científicas de América Latina, el Caribe, España y Portugal

Proyecto académico sin fines de lucro, desarrollado bajo la iniciativa de acceso abierto 
rev.relac.int.estrateg.segur.4(2):39-64,2009

\title{
LA RECONFIGURACIÓN BRASILERA Y EL IMPERIO BRITÁNICO, 1822-1914. ¿DEPENDENCIA O ESTRATEGIA?
}

\author{
Oscar Granados-Erazo*
}

Puede que el cetro caiga de nuestras manos. Puede que accidentes imprevistos estorben nuestros más profundos designios políticos. Puede que la victoria se muestre inconstante con nuestras armas. Pero hay triunfos a los que no sigue derrota alguna. Hay un imperio que esta libre de todas las causas naturales de decadencia. Esos triunfos son los pacíficos triunfos de la razón sobre la barbarie; ese imperio es el imperio inmarcesible de nuestras artes y nuestra moral, nuestra literatura y nuestras leyes.

Thomas Macaulay

\section{RESUMEN}

La inestabilidad europea de principios del siglo XIX, permitió la configuración de las nuevas naciones latinoamericanas; pero en ese proceso se involucró considerablemente el Imperio Británico, el cual gozaba de una fortaleza política y económica

\footnotetext{
* Economista, Universidad Externado de Colombia. Magister en Relaciones Internacionales, Pontificia Universidad Javeriana. Magister en Asuntos Internacionales, Universidad Externado de Colombia. Director Maestría en Geografía, Universidad Militar Nueva Granada. Director Grupo de Investigación de Estudios Históricos y Geográficos, Universidad Militar Nueva Granada. oscar.mge@gmail.com
} 
global. Brasil, en ese avance hacia la modernidad y en esa intensión por consolidar su identidad nacional, permite una vinculación estrecha de los británicos en sus procesos políticos y en la financiación de recursos de capital, que lograron la estructuración de un Brasil de dimensiones continentales. La cercanía británico-brasilera podría mencionarse como una relación de dependencia brasilera o estrategia británica, pero lo que realmente se estructura es una evolución de la diplomacia económica.

Palabras clave: Brasil, identidad nacional, política exterior, diplomacia, imperialismo, inversión extranjera, globalización

\section{ABSTRACT}

The European instability of the early nineteenth century, allowed the configuration of the new Latin American nations, but was involved in that process considerably the British Empire, which enjoyed a global political and economic strength. Brazil, in the progress towards modernity and the intention to consolidate its national identity, allows for a close relationship with the British in their political processes and funding of capital resources, which managed the structuring a Brazil of continental dimensions. The closeness British-Brazilian relationship could be mentioned as a Brazilian dependency relationship or British strategic relationship, but the structure is actually an evolution of economic diplomacy.

Key words: Brazil, national identity, foreign policy, diplomacy, imperialism, foreign investment, globalization

\section{INTRODUCCIÓN}

La llegada de la independencia a América Latina, se convirtió en un proceso que determinaría la construcción de nuevos Estados nación, pero que a la sombra de lo que sucedía en Europa, posiblemente no se consolidaría sino hasta después de varios años. Los acontecimientos previos al Congreso de Viena de 1815, fueron los causantes para que Brasil se constituyera como imperio después de dejar de ser colonia, sin recibir claramente los frutos de la independencia y la libertad que otras naciones americanas ya estaban disfrutando en cierta medida; sin embargo existen elementos que permitieron la consolidación de su identidad nacional.

Aunque el desequilibrio europeo de finales del siglo XVIII y principios del siglo XIX, fue elemento esencial para el fortalecimiento de los procesos independentistas en América, Portugal vivió los embates directamente, ya que sufriría la presión francesa como invasor, la presión española como oportunista, la presión británica como aliado y la presión brasilera como colonia. Después de la firma del Congreso de Viena, Inglaterra logra fortalecer aun más su poder global, económico y 
político, ya que conto con la capacidad e infraestructura para diseñar el proceso de consolidación del sistema internacional en diferentes lugares del mundo y logro que su influencia económica y política fuera determinante para la evolución de varias naciones, incluyendo la configuración del equilibrio europeo, donde Europa experimentó el más prolongado periodo de paz que hubiera conocido antes ${ }^{1}$.

Con la llegada del imperio portugués a suelo brasileño en una magnitud territorial y no colonial, también llegó el imperio británico buscando consolidar su capacidad económica y política en un país que contaba con los mayores recursos de esta parte del continente, y que durante siglos siempre fue foco de intensiones y estrategias por parte de los ingleses y los holandeses. Algo que también se presentó en otros países de América mientras se consolidaba su débil democracia, como es el caso de Argentina, México y Chile.

Había periferias que no formaban parte del Imperio Británico formal, pero cuyos gobiernos estaban convencidos de que la modernización redundaba en el interés de sus naciones. Y una vez convencidos de ello, el capital no tendría más que fluir hacia aquellos lugares desde los bancos británicos, como el de Baring o el de Rothschild. Se construirían puertos o se mejorarían los ya existentes para acoger a los nuevos barcos de vapor o acorazados que vendrían de la metrópoli y volverían a ella en un constate ir y venir; se diseñarían ferrocarriles a los que se suministraría material rodante fabricado en los Midlands; se crearían almacenes y centros procesadores; se instalarían cónsules y agentes comerciales en los lugares más estratégicos con la misión de conectar a los productores con los navieros, de presionar a las autoridades locales para que levantaran las barreras aduaneras, y de proporcionar a los comerciantes inmunidad ante los tribunales de justicia locales ${ }^{2}$.

A pesar de que América se convirtió en un lugar apetecido por los europeos después de sus procesos de independencia, ya que eran lugares importantes para la consolidación de sus intereses económicos; fueron pocos los países que se conectaron rápidamente con el esquema de colonialismo de puertas abiertas del imperio británico y, que a través de su incipiente e ingenua diplomacia acercaron el avance de este imperio a la estructuración de sus naciones, al punto de ser parte de influencias políticas que hacían notar la inexperiencia de las nuevas naciones americanas. Sin embargo, algunos otros países europeos antes de finalizar el siglo XIX y en la carrera por fortalecerse económica y políticamente que se había desatado en Europa, tenían en América del Sur un lugar clave para avanzar económicamente y disfrutar de la explotación de una cantidad de recursos naturales incalculable; por eso el Imperio Británico empezaría a ver una competencia cada vez mayor con la llegada del siglo XX, no solo en la actividad comercial, sino también financiera, mercante, de infraestructura, exploración y explotación.

\footnotetext{
${ }^{1}$ Kissinger (1995) p.74

${ }^{2}$ Schama (2002) p.290
} 
Varios autores han realizado importantes análisis de la evolución de la inversión y la exportación de capital británico en América Latina y en especial en Brasil, como el trabajo de Stone, Platt, Pollard, Cain y Hopkins; algunos trabajos detallan las dificultades o los avances económicos de sectores de la economía como son los trabajos de Leff, Summerhill, Alden y Higman; y otros trabajos como el de Graham que desarrolla la estrecha relación británico brasilera en su avance económico. El propósito de este artículo es revisar, a partir de una verificación histórica, cómo se estructuró la relación entre el Imperio Británico y Brasil durante la época en que los británicos gozaron de su mayor esplendor económico y político como imperio, y los brasileros conformaron su estructura política y diplomática, y su consolidación como el país con mayor potencial económico en este lado de las Indias occidentales, gracias a las bondades de su extenso territorio para abastecer materias primas y diversificar fácilmente sus productos de exportación; convirtiéndose en el mayor abastecedor de recursos de América Latina. De esta forma se plantea que la relación de Brasil e Inglaterra se configura sobre una dependencia estratégica de diplomacia económica y no bajo un esquema unilateral de dependencia brasilera o estrategia británica.

El documento se divide en cuatro secciones; en una primera sección se desarrolla la estructuración política de Brasil y la conformación de su identidad nacional, elementos importantes para interactuar diplomáticamente de forma adecuada en un sistema internacional que avanzaba rápidamente y donde los nuevos países de América no contaban con una experiencia adecuada; en una segunda parte se revisa el momento político crucial de Brasil de configurarse como República en el momento en que el mundo iniciaba un avance globalizador y de estrategias geopolíticas globales, weltpolitik, que culminaría con la Primera Guerra Mundial; en una tercera sección se analiza la vinculación británica en los procesos económicos brasileños y se determina que tan relevante fueron para su configuración como Nación; finalmente una sección con las conclusiones.

\section{LA RECONFIGURACIÓN BRASILERA: DE COLONIA A IMPERIO}

Con la llegada del Regente de Portugal Joao VI y su comitiva de nobles aristócratas en Noviembre de 1807, presionados por los avances de Napoleón en sus territorios peninsulares, el cual buscaba afectar a los británicos y su comercio mediterráneo aplicando su estrategia de Sistema continental; Brasil recibe de pronto toda una clase dirigente muy capaz que, como es natural, se cobra apropiándose de lo mejor que había en el país ${ }^{3}$. Aunque esa conversión de Colonia a Imperio dejo en los nativos un sabor de que su identidad no era lo propuesto por Joao VI con la proclamación del Reino Unido de Portugal, Brasil y Algarves; lo obligaría posteriormente a retirarse de suelos americanos y volver a la península, decisión que se fortaleció con la revolución liberal de Oporto en Agosto de 1820.

En ese momento se vislumbra una independencia del poder central de Joao VI, ya que con la proclamación de Pedro I, primero, como Regente del Brasil y posteriormente como defensor perpe-

\footnotetext{
${ }^{3}$ Ribeiro (1995) p. 135

LA RECONFIGURACIÓN BRASILERAY YLLIMPERIO BRITÁNICO, 1822-1914. ¿DEPENDENCIA O ESTRATEGIA?
} 
tuo del Brasil por parte de la población local; se iniciaría una presión por parte de las Cortes de Lisboa por ordenar el regreso de su Regente a Portugal. Al recibir el apoyo de las diferentes facciones políticas de Brasil, tanto liberales como conservadores, Pedro I decide apartarse de la sucesión al trono de Portugal, no aceptar la imposición política de Lisboa y mucho menos diezmarse con la orden de abolición de la regencia brasilera por parte de las Cortes. Pedro I decide lanzarse a determinar la independencia de Brasil, gracias a ese importante apoyo político local que lo mantuvo como su líder y conciliador.

A pesar de la intención de algunos partidarios de mantenerse unidos a Portugal y a Joao VI, fueron vencidos por las presiones que ejercieron los ingleses sobre Lisboa para que aceptara la independencia del nuevo Estado, recordando su apoyo durante las guerras napoleónicas. Además en Brasil existía una población convencida de la importancia de lograr su independencia, su configuración política y constitucional; así como el fortalecimiento de su identidad nacional.

El apoyo británico que recibieron los brasileños para ser reconocidos como nuevo Estado, tuvo una influencia importante a los intereses económicos de los dos países, pero donde los grandes beneficiados fueron los ingleses al recibir tasas y tarifas preferenciales para sus productos, la apertura de la actividad comercial exclusiva hasta ese momento de Portugal y, el negocio de financiar a Brasil por parte de sus entidades bancarias para el pago de una indemnización a Portugal. Gran Bretaña era virtualmente la única fuente de capital importante para estos países ${ }^{4}$. Esta acción hizo que los ingleses quedaran en buenos términos con los dos países y beneficiaran su economía de intercambio comercial de ultramar. Así mismo e influenciado por la capacidad diplomática inglesa, Brasil ingresa al Concierto Internacional de Naciones con su exitoso tratado de 1825 con Portugal ${ }^{5}$; abriendo las puertas a una estructura diplomática de primer nivel que se fortalecería durante el siglo XIX y le traería importantes beneficios políticos y económicos.

Inglaterra ejerció presión para la abolición de la esclavitud en Brasil poniendo a las exportaciones brasileñas en desventaja con las de las colonias inglesas, algo que para Pedro I era manejable y que era pagado con la cercanía de Inglaterra. La intención del parlamento británico de abolir la esclavitud desde 1807, tenía como claro referente el contrarrestar el avance de los demás países al beneficiar su estructura económica con mano de obra esclava, que le permitiera optimizar su capacidad productiva y de esta forma lograr los beneficios que hasta ese momento había logrado Inglaterra ¿ $\mathrm{O}$ sería una actitud propia de apoyo a la igualdad y la libertad de las personas de raza negra? Inglaterra utilizó una estrategia que redujera las presiones de sus más cercanos competidores globales, a través de una alta extensión de su presencia en el extranjero que, puede ser visto como una expresión de su incapacidad para dominar a sus principales competidores, y en especial para evitar su industrialización ${ }^{6}$.

\footnotetext{
${ }^{4}$ Platt (1980) p. 1

${ }^{5}$ Pereira de Araujo, Azambuja, Ricupero (1989) p. 15

${ }^{6}$ Cain y Hopkins (1980) p.466
} 
El comercio de esclavos para Brasil era lo suficientemente importante para sus actividades económicas, y se vuelve un factor que definirá de ahí en adelante la evolución de su economía con una fuerza de trabajo la cual era administrada por los procesos migratorios de Europa, que brindaban mano de obra barata y con unos niveles de productividad mayores a los que brindaban los esclavos. La caída de la esclavitud le dio a los brasileños un nuevo engranaje a esa identidad nacional, ya que en ese momento toda la población tendría una igualdad humana y no social, que hacia relevante encaminar todos los esfuerzos a que se lograra un fortalecimiento de la actividad económica bajo un nuevo esquema que era diferente al que habían utilizado durante más de 300 años.

Estos dos puntos mencionados anteriormente resaltan que en los primeros años de la independencia, la influencia inglesa en Brasil era profunda y sus objetivos económicos y políticos eran influenciados. Aunque no es en vano mencionar que posiblemente era tal la definición de la identidad nacional de Brasil, que se acercó a Inglaterra, potencia de su momento, para consolidar su estructura económica y forjar unas características que le podían dar la posibilidad de fortalecerse como Nación independiente, a costa de ceder un poco en sus pretensiones. Este se puede confirmar con la intención de la geopolítica británica, cuando se presenta la revuelta de las provincias unidas del Río de la Plata, territorio que había sido incorporado al Imperio Brasilero años antes; que se convierte en disculpa para lograr su objetivo de establecer un Estado tapón entre Argentina y Brasil y reducir las ambiciones brasileñas en el Río de la Plata ${ }^{7}$.

Es importante reconocer, que Inglaterra posteriormente se consolidó en los procesos comerciales y productivos y en la financiación del gobierno brasilero, moldeando sus decisiones de inversión e infraestructura que beneficiaran a sus hombres de negocios y banqueros. Sus presiones directas ya no eran tan frecuentes; la identidad nacional de Brasil, se veía más afectada por las decisiones del Emperador, que realmente por la población que era la mas interesada por mantenerse independiente y era la que buscaba defender y manifestar su inconformismo por decisiones tales, como acercarse nuevamente a Portugal con la muerte de Joao VI y la directa sucesión de Pedro I emperador de Brasil en el Reino que dejaba su padre. Los brasileros lograron sobrepasar esos intereses del gobierno de depender nuevamente de Portugal y obligan a través de sus revueltas a la abdicación de Pedro I en abril de 1831. Los intereses nacionales estuvieron por encima de los intereses monárquicos, aunque en muchas ocasiones pudieron llevar a la secesión de algunas provincias, por la misma configuración de los intereses de algunos grupos regionales y al fortalecimiento de movimientos separatistas, como los que se presentaron en la zona de Para en el valle del Amazonas y en Río Grande do Sul, lugar estratégico para los intereses económicos de Brasil, con la revolución Farroupilha de tendencia liberal que buscaba conquistar una autonomía provincial ${ }^{8}$; los cuales serian aminorados con el incremento del poder de las Provincias a través de la enmienda constitucional de 1834.

Con la llegada al poder de Pedro II en 1840, realmente se logró unificar la dividida elite que hacia que Brasil se viera afectado por las diferencias de cada facción y diera, como posible resultado, un

\footnotetext{
${ }^{7}$ Skidmore y Smith (2001) p. 140

${ }^{8}$ Pereira de Araujo, Azambuja y Ricupero (1989) p.40

LA RECONFIGURACIÓN BRASILERA YEL IMPERIO BRITÁNICO, 1822-1914. ¿DEPENDENCIA O ESTRATEGIA?
} 
desmembramiento del territorio brasileño. La monarquía tenía la capacidad de consolidar todos los intereses regionales desde un poder central, algo con que los políticos locales aun no contaban. Para lograr que las diferencias se consolidaran en los partidos políticos y no en la fragmentación territorial, en 1850 emergen dos nuevos partidos del anterior Partido brasileño: el partido liberal y el partido conservador.

Ya para esta época Brasil se ponía a prueba no solamente a su interior, sino ahora en el ámbito internacional, con la primera dificultad en su política exterior, con respecto a la situación que se venían presentando en la Cuenca del Río de la Plata, entre Paraguay, Uruguay, Argentina y Brasil. Cuando Juan Manuel de Rosas de Argentina estableció su intención de controlar todo el trafico del Río de la Plata y defender la independencia de Uruguay con un claro objetivo de abrir esa cuenca a la navegación internacional y ampliar los intereses económicos argentinos, lo cual ocasionaba un trastorno a los intereses económicos y comerciales de Brasil sobre todo a las provincias del sur y al acceso de la cuenca hidrográfica del Río de la Plata formada por los ríos Paraná, Uruguay y en menor medida con los ríos Ibicuy y Negro. Sin embargo, Brasil con el ánimo de fortalecer su avance político en la zona, también se involucró en la guerra interna de Uruguay, donde se había posicionado en el sector comercial y financiero; y para esto apoya la facción de los Colorados la cual hasta ese momento prevalecía en su lucha contra los Blancos.

Aunque el detonante fue la interacción que se presentó en esta zona con la estrategia de Rosas, ya que involucró a los franceses y británicos para que apoyaran su causa a través de prebendas económicas; sin embargo los europeos, que tenían grandes intereses en la zona, acudieron al apoyo de los rebeldes argentinos para deponer del poder a Rosas. Pero inmediatamente las intenciones políticas se veían cada vez más fuertes debido a que los intereses económicos en esta cuenca hidrográfica eran relevantes para cualquier país que la quisiera dominar. Es en ese momento que el Dictador paraguayo Solano López, el cual había apoyado a los Blancos en Uruguay que ya se encontraban al frente del poder en Uruguay toma la iniciativa de invadir a Argentina y Brasil (Río Grande do Sul) países que estaban apoyando nuevamente a los Colorados. Esta invasión se da en 1865, causando grandes reveses militares; lo que condujo a que Brasil buscara ampliar su fuerza militar y la influencia que esta tuviera en las decisiones políticas, además de un avance en el autoritarismo del Emperador $^{9}$. Con la guerra paraguaya se pone a prueba la fortaleza de la identidad nacional y la importancia de los intereses económicos brasileños que se fueron definiendo a partir de ahí como elementos relevantes para mantener su posición en la región y lograr consolidarse como Nación. Su intención de fortalecerse como país de primera línea en el contexto regional, así como su capacidad de responder ante cualquier eventualidad local e internacional, determino un avance en su estructura de financiación y gasto publico que, seria parte fundamental en ese objetivo; generando altos impactos en el gasto destinado al pago de deuda y el gasto militar, que desde el siglo XIX ha sido un rubro importante en la configuración estatal de Brasil. (Ver Tabla 1.1).

${ }_{9}^{9}$ Skidmore y Smith (2001) p. 142 
En ese momento ya se había iniciado una fuerte actividad económica mundial e intercambio comercial, la llamada primera era de la globalización, en donde Brasil no podía ser ajeno a ese avance y aprovechar su gran potencial económico, que durante tanto tiempo había sido parte importante de su comercio exterior; y era el momento de solidificar su lugar por lo menos económico en el sistema internacional. Durante esa primera era de la globalización, el comercio internacional creció a una tasa anual de $4 \%$, pasando del $10 \%$ del PIB global en 1870 a más del $20 \%$ en 1914; mientras que los flujos internacionales de capital crecieron anualmente al $4.8 \%$ y se incrementaron del $7 \%$ del PIB global en 1870 a casi el $20 \%$ en $1914 . .^{10}$

Tabla 1.1

LOCALIZACIÓN DEL GASTO PUBLICO CENTRAL 1831-1885

$(\%)$

\begin{tabular}{|l|r|r|r|}
\hline Periodo & \multicolumn{1}{|c|}{$\begin{array}{l}\text { Ministerio de } \\
\text { Finanzas * }\end{array}$} & \multicolumn{1}{c|}{$\begin{array}{l}\text { Ministerios } \\
\text { Militares }\end{array}$} & \multicolumn{1}{c|}{$\begin{array}{c}\text { Ministerios } \\
\text { Civiles }\end{array}$} \\
\hline $1831-1863$ & 35 & 41 & 23 \\
\hline $1864-1870$ & 28 & 55 & 18 \\
\hline $1871-1885$ & 38 & 22 & 40 \\
\hline$*$ Incluye servicio de la deuda \\
\hline
\end{tabular}

Fuente: Leff (1972) p. 503

Con los avances económicos de la globalización y la ampliación del espectro académico, político y cultural de algunos brasileros, la identidad nacional dio un giro sorprendente al iniciarse una entrada a la política de nuevos militares y jóvenes educados interesados en direccionar la estructura política de Brasil y acabar, no solamente con la esclavitud y el rezago social, sino con la monarquía que no era más que un anexo al poder colonial que ejerció Portugal durante mas de 350 años, y que se había convertido en un largo periodo de más 65 años, encabezado por los herederos al poder de Portugal y de algunos grupos regionales interesados en las bondades de la monarquía. De esta forma, estas fuerzas progresistas y republicanas lograron con el apoyo del ejército esquemas que determinaran la necesidad de cambio y la importancia de que las Fuerzas militares se consolidaran como una fuerza relevante y determinante en la política brasileña.

La monarquía valoró la intención de cambio de los progresistas pero su aceptación no fue lo suficientemente profunda, lo mismo que sus reformas políticas que lo único que buscaban era mantenerse en el poder, a pesar que la Cámara ya contaba con mayoría republicana y liberal, dos vertientes políticas que estaban lejos de sus conceptos políticos. En ese momento los militares iniciaron una conspiración contra la monarquía; un golpe militar liderado por Deudoro da Fonseca, condujo finalmente a la abdicación de Pedro II y a su exilio a Portugal, proclamando la República de Brasil

\footnotetext{
${ }^{10}$ Mishkin (2005) p.1

LA RECONFIGURACIÓN BRASILERA YEL IMPERIO BRITÁNICO, 1822-1914. ¿DEPENDENCIA O ESTRATEGIA?
} 
el 16 de Noviembre de 1899. Se iniciaría una nueva época para el fortalecimiento de la identidad política que durante los últimos años logro que los habitantes tuvieran una igualdad humana y que el país fuera dominado por las estructuras políticas legitimas que se vivían ya por esos días en América y que se fundamentaban en la interacción de los partidos políticos y en la definición de programas que se sustentaban en la democracia y no en la concertación del poder exclusivamente en una sola persona: El Emperador.

Es importante mencionar que el progreso económico que obtuvo Brasil en la época imperial, sin entrar a revisar las fuentes de ese avance económico lo cual se hará en la tercera sección, fue un progreso que permitió que Brasil se convirtiera en un abastecedor de diversas materias primas, al punto de generar en varias ocasiones bonanzas exportadoras en productos desde la azúcar, pasando por el café y el caucho.

Sin embargo, eso no generó como resultado un aumento del valor económico o de la competitividad de Brasil, ya que otros países lograron avanzar aun más en su crecimiento económico con menores recursos productivos y naturales. Un ejemplo de este fue el deterioro de la tasa de cambio; el milreis valía, en libras esterlinas, 70 peniques en 1808; gracias a la guerra napoleónica había subido a 85 peniques hacia 1814; después comenzó a bajar a 49 peniques en los días de la Independencia, en 1822, y a 25 en 1860. La guerra de secesión en los Estados Unidos le trajo una breve mejoría, descendiendo luego a 18 peniques, su más baja cotización antes del fin de la esclavitud y el Imperio, en 1888 y 1889 respectivamente.

Tabla 1.2

PRINCIPALES INGRESOS POR EXPORTACIONES

Participación \%

\begin{tabular}{|l|r|rr|}
\hline Producto & $\mathbf{1 8 2 1 - 1 8 2 3}$ & $\mathbf{1 8 7 1 - 1 8 7 3}$ & $\mathbf{1 9 1 2 - 1 9 1 4}$ \\
\hline Algodón & $\mathbf{2 5 , 8} \%$ & $16,6 \%$ & $\mathbf{2 , 9 \%}$ \\
\hline Azúcar & $23,1 \%$ & $12,3 \%$ & $0,3 \%$ \\
\hline Café & $18,7 \%$ & $50,2 \%$ & $60,4 \%$ \\
\hline Cuero & $13,5 \%$ & $6,4 \%$ & $4,7 \%$ \\
\hline Tabaco & $3,2 \%$ & $3,2 \%$ & $2,6 \%$ \\
\hline Cacao & $0,6 \%$ & $0,8 \%$ & $2,9 \%$ \\
\hline Caucho & $0,0 \%$ & $5,3 \%$ & $17,4 \%$ \\
\hline Erva Mate & $0,0 \%$ & $1,6 \%$ & $3,3 \%$ \\
\hline
\end{tabular}

Fuente: Leff(1973)

Brasil se convirtió en una despensa necesaria para los ingleses, los procesos productivos de sus bienes más relevantes en el comercio internacional se ajustaron a las variaciones del consumo interno británico (Ver Tabla 1.2) y posteriormente a una demanda global. Su ampliación hacia otros mercados se daría de una forma tardía, generando una pérdida de participación en el comercio internacional. 


\section{LA TRANSICIÓN POLITICA Y LA RECONFIGURACIÓN REPUBLICANA}

En ese momento el mundo vivía un cambio en sus intenciones geopolíticas, ya con el Congreso de Berlín de 1885, la configuración de los territorios africanos cambió, y la imposición reguladora de los británicos durante gran parte del siglo XIX empezó a transformarse, dándole cabida a dos nuevos regentes globales: Estados Unidos y Alemania; sin embargo los británicos se mantendrían como los principales socios económicos de los brasileros.

En Brasil, la doctrina Monroe proclamada un año antes de ser reconocido como Nación por los Estados Unidos, empezaba a influir en los procesos políticos brasileños; así como en la interacción económica, ya que Estados Unidos después de una larga reorganización económica generada por la guerra de secesión, se encontraba listo para avanzar en su intención global de beneficiarse del intercambio comercial y las inversiones internacionales, empezando por su territorio más cercano. Alemania después de su reunificación en 1870, y siguiendo el ejemplo de las bondades del imperialismo británico, inicio un avance en aquellos sitios en donde su potencial económico se podía desarrollar; el cual anteriormente lo hacia de la mano de las compañías mercantiles y los bancos ingleses. Con el Segundo Reich era necesario y estratégico hacerlo por sí mismo, y en ese momento el comercio con Suramérica se consolida en Brasil y Argentina, a través de compañías mercantiles y agencias de entidades financieras; lo cual soportaba también el proceso previo de migración alemana hacia el sur de Brasil y Norte de Argentina, que había constituido las colonias agrícolas y comerciales años antes, y que también permitiría el éxito de las compañías mercantes alemanas en los puertos del sur de Brasil ${ }^{11}$.

La proclamación de la República de Brasil cambio un esquema político que durante mas de sesenta y cinco años logro establecer varios elementos que forjaron la identidad brasileña, pero que aunque eso se diera no lograría que parte importante de la población, como los militares, las nuevas clases terratenientes de las zonas de expansión económica y los nuevos letrados del país, aceptaran los lineamientos políticos que determinaba el Emperador los cuales estaban alejándose de lo que ya se buscaba en los escenarios políticos locales e internacionales del momento. Con este avance se iniciaría una nueva etapa en la identidad nacional brasileña, ya que el proceso político se enfocaba hacia la pluralidad, la autodeterminación y autonomía de un pueblo que estaba sujeto a los intereses de una familia monárquica que tenia relación directa con el poder de Portugal, y que este a su vez mantenía estrechos lazos con los británicos.

De esta forma, se inicia el cambio de un esquema centralizado hacia una nueva forma de organización política que le dará a la identidad nacional un fuerte afianzamiento, aunque se este dejando de lado un elemento cohesionador como es el poder político del centralismo; pero es realmente la identidad nacional que hasta ese momento gozaba Brasil la que le dio y mantuvo el territorio unido con los nuevos avances de la estructura federal, que nunca se vio como un avance hacia la secesión sino mas bien para una autonomía bajo esquemas claramente definidos de identidad nacional.

\footnotetext{
${ }^{11}$ Forbes (1978) p.391
}

LA RECONFIGURACIÓN BRASILERA YEL IMPERIO BRITÁNICO, 1822-1914. ¿DEPENDENCIA O ESTRATEGIA? 
Con la llegada de Deodoro de Fonseca y los militares al poder, dieron al país una transición política que no era lo que realmente se necesitaba, pero se convirtió en una transición que le generaba orden a las posibles intenciones de algunos miembros de la sociedad de sacar ventajas de la situación. Aunque de forma externa los Estados Unidos lograron sacar provecho de la situación, ya que influyeron fuertemente en las decisiones políticas que le daban beneficios a sus inversiones e intereses económicos en suelos brasileños, además de la influencia en el sistema de gobierno, ya que fue a partir del modelo norteamericano que se definió el sistema de gobierno federalista, aunque de cierta forma mas moderado que el que regia en los Estados Unidos, algo que el superministro de la época Rui Barbosa implemento y presiono para que se diera desde su cartera del Ministro de Hacienda.

Así mismo la nueva república llena de libertad, requería de una nueva estructura monetaria y financiera, estableciendo la emisión de moneda por parte del gobierno; además de permitir el establecimiento de empresas que darían mayor fortaleza a la capacidad económica que el Imperio medianamente había logrado con el apoyo de los bancos europeos en especial los ingleses. Sin embargo solamente se convirtieron en vehículos especulativos que no dieron la profundidad necesaria a la capacidad económica. La explotación de los recursos minerales quedó en mano de los particulares, ya que el subsuelo pasa a propiedad de los dueños de la tierra y no de la nación como sucedió en la era colonial e imperial, algo que tenia que ser solucionado inmediatamente lo cual se hizo con el Código de Minas en 1891.

Adicionalmente, la nueva República debía contar con una infraestructura política que soportara una nueva forma de gobierno y se alejara de los esquemas imperialistas; por esta razón se llamó a una Asamblea constituyente que culminaría con una Constitución en 1891 la cual no se apartó de la Constitución de 1824, ya que mantenía el esquema centralista y unitario pero con privilegios a los Estados, anteriormente provincias; dando un importante poder a los Estados económica y políticamente fuertes e influyentes, como Sao Paulo, Minas Gerais, Río Grande do Sul y Río de Janeiro.

A partir de ahí el sistema político de la República se sustentó sobre los tres núcleos de poder. En la base de la pirámide estaban los contentados locales, los Ilamados coroneis, que controlaban la población rural de una área determinada (eran los terratenientes y latifundistas que manejaban amplias zonas de tierras). En un nivel intermedio estaban las oligarquías estatales, constituidas en mayor o menor medida por federaciones de coroneis, cuyas funciones diferían institucionalmente de las de los coroneis cuando actuaban aisladamente. En el pináculo de la estructura de poder estaba el gobierno federal, que era producto de una alianza entre las oligarquías de los estados más importantes y, por lo tanto, expresión de una federación de oligarquías ${ }^{12}$.

La inconformidad por parte de algunos miembros de las fuerzas militares por la llegada al poder del Mariscal Floriano Peixoto en reemplazo como Vicepresidente de la renuncia del Presidente Deodoro da Fonseca, ocasionó ciertas revueltas que fueron sofocadas rápidamente por las fuerzas leales a

${ }^{12}$ Fausto (2000) p.422 
Peixoto, el Mariscal de Hierro. Sin embargo, la escuadra de la Marina anclada en Río de Janeiro en septiembre de 1893, se levantó contra Peixoto, aduciendo la necesidad de restaurar el poder de la constitución por encima de los intereses particulares de algunos militares. Aquí se presentó el primer diferendo internacional cuando la subordinación de los militares se traslada a barcos portugueses, ya que estos lo reciben de forma de asilo político y el gobierno de Brasil decide romper relaciones con Portugal; pero a su vez navíos de diferentes nacionalidades, americanos, ingleses y portugueses reclamaron la defensa de sus compatriotas que vivían en la ciudad y llegaron a un entendimiento con Floriano Peixoto ${ }^{13}$. Todas las revueltas y hostilidades fueron controladas dando muestra de la fortaleza de la República, ya que se mantuvo como una sola unidad política sin secesiones visibles y salvaguardando una identidad, por encima de los intereses particulares y de algunas regiones que en algunos momentos pusieron en dificultades la unidad del territorio brasileño.

Con los militares en el poder en esa transición política, le permitió a Brasil la posibilidad de mantenerse unificada, ya que su mano dura posiblemente evitó lo que podría haber sucedido cuando muchos territorios gozaban de la capacidad económica, política y militar de constituirse en un nuevo país; algo que para muchos se evito en la constitución de 1891 cuando no se permitió a los Estados tener su propio ejercito estatal. El poder de Da Fonseca y Peixoto se pueden establecer como dos periodos relevantes en el mantenimiento de la identidad de Brasil como nación y pueblo. En 1894 se darían elecciones presidenciales y el poder civil toma las riendas de un país que se mantenía por la fuerte represión, algo que con la llegada de Prudente de Moráis no cambiaría, ya que el episodio de la revuelta de Canudos en el nordeste del país, fue acallada con una matanza de dimensiones históricas, mostraron la intención del gobierno de reducir los procesos separatistas y de sofocar las revueltas a cualquier precio, que afectaran la unidad y el control del país.

El cambio más importante durante este periodo se dio en dos aspectos: la economía y la diplomacia. La economía tuvo un avance importante ya que se inició el proceso de diversificación agrícola que hasta ese momento se había concentrado en la producción cafetera y donde algunas zonas del países se convertirían en nuevos centros económico agrícolas como los Estados de Amazonas y Para, que se vieron beneficiados con la producción de caucho y el aumento del precio internacional que paso de $£ 182$ por tonelada en 1870 a $£ 512$ por tonelada en 1911 , además de un aumento en la exportación que pasó de 6.591 toneladas en 1870 a 38.547 toneladas en 1911, siendo para Brasil el segundo producto de exportación por ingresos, durante el tiempo que la oferta y los precios se mantuvieron altos. El café era el producto más importante de exportación, ya que en varios momentos de la historia de esa época, Brasil suministraba más de la mitad de todo el café vendido en el mercado internacional ${ }^{14}$.

\footnotetext{
${ }^{13}$ Iglesias (1995) p.26

${ }^{14}$ Dean (2000) p.342

LA RECONFIGURAGÓN BRASILERAYELIMPERIO BRITÁNICO, 1822-1914. ¿DEPENDENCIA O ESTRATEGIA?
} 
Grafica 2.1

Oficinas Bancarias internacion ales en Suramérica

1880-1913

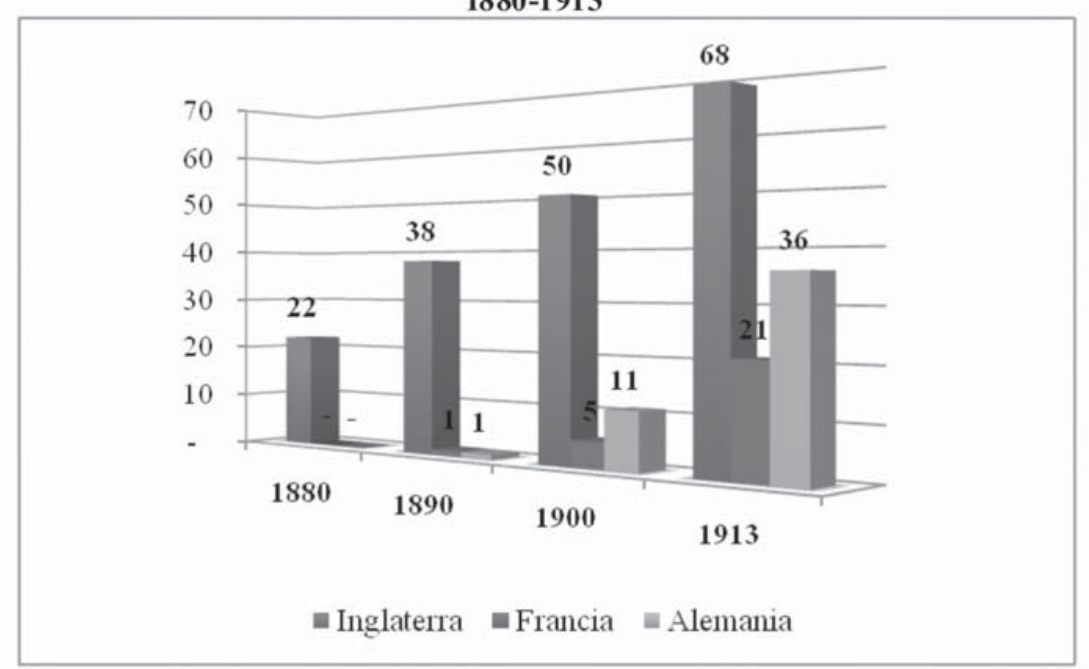

Fuente: Battilossi (2005) p.15

El ascenso y el descenso repentino también se vivió en otros productos agrícolas como la Caña de azúcar, cacao y el algodón, pero que se convirtieron en importantes productos para el comercio brasileño con ultramar, ya que el algodón suministraba en los finales de la colonia el $10 \%$ del mercado mundial, y los otros productos veían a Brasil como un abastecedor importante en el mercado mundial; es decir, Brasil contaba con varios productos importantes en el comercio exterior lo que lo convertiría en una potencia agrícola regional y en algunos productos una potencia mundial; pero se fue perdiendo la ventaja por los bajos costos en otros centros de producción mundial y por el alto costo tributario que se vivió en aquella época, además de no contar con el capital para ampliar el espectro económico, por esta razón posteriormente el atraer capital extranjero para nuevas actividades productivas se convertiría en algo vital para el crecimiento económico del país. Aunque existe un elemento adicional que redujo los ingresos del exterior y fue la imposición de una devaluación forzada por parte de la casa bancaria de los Rothschild en (mayo y junio de) 1898 para otorgar un crédito $^{15}$, en el momento en que Brasil se disponía a refinanciar su deuda internacional y que venia gestionando un desequilibrio macroeconómico que se había iniciado con la república y el contagio por la crisis financiera de Argentina de 1890, generando un deterioro en su nivel de riesgo de mas del $54 \%$ en la ultima década del siglo $\mathrm{XIX}^{16}$.

Adicionalmente, para mantener los ingresos del café fue necesario la imposición del Convenio de Taubate (1906), donde los Estados cafeteros compraban el café, lo almacenaban y esperaban que el

${ }^{15}$ Ibid. p. 346

${ }^{16}$ Triner (2001) p.20 
precio compensara el costo; todo esto a través de la contratación de créditos externos con bancos europeos y estadounidenses, los cuales se verían beneficiados debido a que los créditos eran avalados por el gobierno federal. Este procedimiento tuvo éxito y benefició a todos los que se involucraron en este proyecto, al punto de que los bancos internacionales ampliaron su presencia en la actividad productiva brasileña así como en la Argentina, incrementando su cantidad de oficinas en Suramérica de 22 en 1870 a 125 en $1913^{17}$ (Ver Grafica 2.1); así como el avance en la creación de empresas, once empresas habían recibido el permiso para constituirse en 1851 y durante los años de 1852-59 otras 135 empresas recibieron sus permisos, en contraste a un total de cuatro durante el periodo 1838-5018. El Convenio de Taubate finalizó con la gran depresión económica mundial en 1929.

De esta forma la política exportadora de Brasil no siempre fue exitosa lo que en ocasiones trastornó sustancialmente el avance de un país con vocación exportadora natural, que pudo ser fuerte desde la misma época en que se instauró la república, pero por la importante intervención de las oligarquías por buscar proteccionismos al interior del país y los impuestos a las exportaciones, condujo a que no se lograra un mejoramiento en la productividad, en la competitividad en los mercados mundiales y en la apertura de nuevos mercados; así como la resignación de ser una economía satélite de los Británicos, que ya para 1870 era un $40 \%$ de las exportaciones brasileras y de un 15\% para $1900^{19}$. Sin embargo, al interior del país la clientela se incrementó sobre el aumento de la influencia de la migración de colonos europeos con nuevas necesidades y solicitudes en el mercado interno ${ }^{20}$. Adicionalmente, el sistema mundial de comercio e inversión en el que se basaba la orientación exportadora de Brasil sufrió un tremendo revés con la primera guerra mundial ${ }^{21}$, ya que no solamente vio reducido sus ingresos por exportación sino también, por un sobrecosto en los bienes importados, lo que genero brotes inflacionarios y adicionalmente una disminución en los ingresos del gobierno que casi lo lleva a su primera declaración de moratoria en octubre de 1914, gracias a un crédito de salvamento obtenido en Inglaterra.

La constitución de 1891 también dio a la economía un elemento vital para que los Estados organizaran su propia estructura económica y su desarrollo, es así como algunos estados como Sao Paulo contrataron deuda por encima de lo que lo hacia el gobierno nacional e impusieran en muchas ocasiones los presidentes que estarían en el poder los siguientes cuatro años. Sao Paulo y Minas Gerais eran los estados mas importantes, los cuales serian acompañados posteriormente por Río Grande do sul; en un segundo nivel estaban Bahía, Río de Janeiro y Pernambuco, que servían como bases de poder para nominaciones presidenciales disidentes ${ }^{22}$.

\footnotetext{
${ }^{17}$ Battilossi (2005) p.15

${ }^{18}$ Graham (1968) p.25

${ }^{19}$ Abreu (2005) p.9

${ }^{20}$ De Azevedo (1944) p.57

${ }^{21}$ Dean (2000) p.347

${ }^{22}$ Skidmore y Smith (2001) p. 153

LA RECONFIGURACIÓN BRASILERAY ELIMPERIO BRITÁNICO, 1822-1914. ¿DEPENDENCIA O ESTRATEGIA?
} 
Con la adhesión de Brasil al bando de los aliados en la Primer guerra mundial trajo consigo una caída de las inversiones de su segundo inversionista y prestamista de la época: Alemania, y una serie de industrias que fueron confiscadas por la imposición de Inglaterra. A cambio recibiría una flota mercante alemana que se encontraba en puertos brasileños compensando la perdida de varios recursos depositados en bancos alemanes y lo mas importante un debilitamiento de sus destinos exportadores y de sus abastecedores de crédito, que ya no era lago exclusivo de los ingleses.

La diplomacia durante la primera república empezó a construirse bajo una tradición portuguesa como una diplomacia de escuela, en contraste con una accidental y descocida diplomacia de la repúblicas vecinas, confiada a homenajes políticos, de prelación desigual, y desviándose a confluencias partidistas ${ }^{23}$. El sistema diplomático brasileño se establecía, a pesar de las variaciones drásticas que se dieron en los primeros años de la República, como una línea de conducta que se flexionaba ligeramente con las alteraciones institucionales, algo que si sucedía con los demás países afectando los procesos de negociación de límites y fronteras. Sin embargo, el elemento más importante en la identidad nacional de Brasil en el aspecto diplomático se dio con la aparición de José María da Silva Paranhos, Barón de Río Branco; uno de los personajes más importantes en el enfoque de la diplomacia y la tradición que hoy por hoy tiene el Palacio de Itamaraty; aunque su enfoque traía la tradición portuguesa y los avances de Quintino Bocayuva y Joaquim Tomas do Amaral Vizconde de Cabo Frío que fueron los primeros ministros de relaciones exteriores bajo un esquema político diferente al imperio, dieron los avances iníciales en una identidad de lograr los acuerdos diplomáticos y fronterizos a través de la doctrina clásica del arbitramento, pero que en el ciclo del Barón de Río Branco se logró una integración territorial y la definición de los contornos geográficos que tiene Brasil hoy por hoy y que se fueron perfeccionando con el pasar del tiempo pero en ningún momento en replantear lo que ya se había hecho durante esta época.

Así mismo el manejo de los asuntos fronterizos y de entendimiento con los demás países, se vislumbraba desde la presidencia con una política amistosa, pacifista y de cordial entendimiento de los presidentes con los países con que colindaba; además de convertirse en un país que equilibraba las fuerzas en el continente suramericano; ya que en ese momento de su vida diplomática era tiempo de definir las intenciones de preservar la paz, por una demostración previa y elocuente de neutralidad justificada tanto por el desinterés nacional acerca de contienda entre naciones amigas, como por las circunstancias internas de déficit publico y de la reorganización lenta de las fuerzas armadas $^{24}$. En palabras del presidente Campos Salles «La diplomacia es como una pintura, un arte, los grandes maestros, pueden dar gran relevancia al contorno de sus figuras y sus paisajes. El arte de la diplomacia es de líneas menos acentuadas, como nuestros grisailles y por eso sus actitudes no siempre son entendidas y bien apreciadas por la mayoría de los jurados ${ }^{25}$. Con el Barón de Río Branco también se logro el acercamiento con los Estados Unidos, la coherencia diplomática y el sentido continental a que Itamaraty se había mantenido fiel hasta ese momento.

${ }^{23}$ Calmon (1939) p. 127

${ }^{24}$ Ibíd. p. 133

${ }^{25}$ Ibíd. p. 135 
Sin embargo algo que determino realmente la claridad diplomática y la identidad nacional fue las definiciones territoriales con potencias de primer nivel y sus posesiones en el continente suramericano: las Guayanas en donde estaban involucrados los franceses, ingleses y holandeses; los cuales deseaban ampliar su territorio hasta la costa del río Amazonas, es decir, entregar los territorios del hoy estado de Amapa y parte del Estado de Para; y aun mas cuando entre los ríos Araguari cerca de la desembocadura del Río Amazonas y el río Oiapoque se encontraron yacimientos de oro en una área que aun se encontraba en litigio, a pesar de que eran posiciones brasileñas que se habían establecido con el Tratado de Utrecht de 1713 y el Tratado de Madrid de 1750. Francia no cedería ante sus intenciones de ampliar su territorio en Suramérica aprovechando la intención de los pobladores locales de declararse independientes y enviaron hombres que aplacaran esa rebelión. Sin embargo, Brasil al ver una posible invasión en sus territorios del nordeste, solicito un proceso de arbitramiento frente a Suiza para exigir sus derechos sobre una zona de mas de 200mil kilómetros cuadrados que era parte de su territorio desde la época colonial, de esta forma el Laudo arbitral de 1900 dio por terminada las intenciones de ampliar los territorios franceses en la zona, dando muestra de la capacidad diplomática de Brasil en solucionar sus diferendos fronterizos a través de los procesos de arbitramento. Algo similar ocurriría con Inglaterra y su posesión en Suramérica, Guyana, en donde su intención de llegar hasta el río Amazonas quedo sellado con un laudo arbitral que le beneficio pero que posteriormente seria protestado por Brasil y se quedaría como zona en litigio hasta el acuerdo de 1926.

Otra acción diplomática de primer orden en la reconfiguración republicana, fue la adquisición de la región de Acre que por medio de la labor del Barón de Río Branco se retomo una región que, aunque estaba establecida en el Tratado de Madrid de 1750, el gobierno boliviano le había impuesto tarifas arancelarias a las mercancías que salían de la zona y en donde para lograr presencia había entregado sus intereses a la administración fiscal privada de los estadounidenses e ingleses con la compañía Bolivian Syndicate of New York a través del Tratado de Aramayo de 1901. Para esto el gobierno de Brasil acudió en auxilio de sus pobladores que se habían levantado contra las autoridades bolivianas y busco a través del desplazamiento de tropas utilizar varias cartas mas allá de las diplomáticas si la situación se complicaba y mencionar que el Gobierno de Bolivia no se encontraba facultado para administrar dicha zona ${ }^{26}$; a pesar de eso el presidente boliviano Placido de Castro también desplazo sus tropas a la zona, generando el rompimiento de relaciones diplomáticas entre los dos países. La labor diplomática llego al acuerdo de ceder a Brasil un territorio de 191.000 km², a cambio de una indemnización de dos millones de Libras esterlinas a Bolivia, 110 mil libras a Bolivian Syndicate, la cesión de territorios cercanos al Estado de Mato Grosso donde habitaban bolivianos y la construcción de una línea férrea entre Porto Velho y Guajara-Mirim ciudades brasileñas, que les permitieran a Bolivia participar del comercio amazónico, todo esto a través del Tratado de Petrópolís de Noviembre de 1903.

En esta época de la historia brasileña, la capacidad diplomática se vivió en todas sus facetas, ya que en un gran porcentaje se solventaron varios litigios fronterizos que aun no se habían solucionado y adicionalmente se convirtió en el mayor representante para los intereses de las potencias en la primera guerra mundial en

${ }^{26}$ Goes (1991) p. 167

LA RECONFIGURACIÓN BRASILERAY EL IMPERIO BRITÁNICO, 1822-1914. ¿DEPENDENCIA O ESTRATEGIA? 
Suramérica; además de ser participe activo en la Conferencia de Paz que daría origen al Tratado de Versalles y posteriormente de la Sociedad de Naciones creada en 1920, de la cual se retiro en 1926.

Al interior del país es importante mencionar que los acuerdos políticos entre los estados más poderosos de Brasil Ilamados Café con Leche, determinó la inconformidad de varios sectores políticos y regionales que iniciarían a mostrar su descontento a través de protestas y manifestaciones, ya que el poder se había centralizado en Sao Paulo (Café) y Minas Gerais (Leche) dejando de lado políticos de tradición e intereses que en muy pocas ocasiones eran representados por los políticos de estos dos estados. Durante esta época la llegada al poder de políticos de diferentes estados se daba por ser formula vicepresidencial que debía asumir el poder o porque posiblemente podría ser el político indicado para contrarrestar un poco el abuso de la imposición del acuerdo del Café con leche, que aun se veía como una imposición mas corrupta y elecciones manipuladas como es la elección de Epitacio Pessoa oriundo del Estado nororiental de Paraiba.

Este sistema de elección mostraba una ruptura política de dimensiones incalculables, ya que se había mantenido la burocracia y la corrupción del imperio, que se desataría en un cambio profundo en los siguientes años, siendo 1922 una línea divisoria que marca el inicio de la ruptura con la República oligárquica, coronelista ${ }^{27}$, y que conduciría a que los tenientes y la clase media entraran a formar parte de una futura lucha armada en contra del régimen burocrático y oligárquico del café con leche, a través de un golpe de estado en 1930 que se gesto después de que las elecciones fueran ganadas inesperadamente por Julio Prestes y se dejará a un lado la Alianza Liberal de Getulio Vargas, la cual posteriormente llegaría al poder con la ayuda de los militares en octubre de ese mismo año y se entraría a una época de reformas políticas, populismo y de una alta concentración de poder en cabeza de una sola persona como fueron las reformas de 1937 y el Ilamado Estado Nuvo.

\section{LA RELACIÓN ECONÓMICA BRASIL-INGLATERRA: ¿DEPENDENCIA O ESTRATEGIA?}

Cuanto mayor sea la extensión del mundo que ocupemos, mejor irán las cosas para la raza humana. Cecil Rhodes

¿Realmente cual fue la interacción económica y la posible vinculación británica en esa reconfiguración política planteada anteriormente? Es una pregunta que debe resolverse revisando las cifras económicas que hicieron de Inglaterra un referente importante en esa configuración. Aunque no se debe desconocer la agresividad del avance económico alemán y mucho menos la intención estadounidense de participar en ese importante socio económico que podría ser Brasil; la relación con el Imperio Británico y su capital fue trascendente en la configuración económica de Brasil durante 1822 a 1914; sin embargo es pertinente mencionar que en las ultimas décadas del siglo XIX, se fortalecería el avance de Argentina como principal referente de inversión británica en

\footnotetext{
${ }^{27}$ Iglesias (1995) p.55
} 
Suramérica, pero mas como un proceso de abastecimiento de bienes ajustados a las necesidades europeas, y no globales como si lo podía establecer la economía brasilera.

La exportación de capital británico, se consolidaría con la importante acumulación que hizo durante la primera parte de la revolución industrial, sin embargo este proceso se consolidó con el avance casi único de su economía durante gran parte del siglo XIX, y un fortalecimiento de la liquidez de su mercado financiero que conduciría a ampliar los horizontes económicos y de rentabilidad de los inversionistas.

Es importante determinar, más allá de la acumulación de capital por las actividades manufactureras y comerciales, cuáles son las principales razones para el avance de la liquidez en el mercado británico. El primer punto es la culminación de un proceso de guerra, que había azotado a Europa por más de 150 años después de los tratados de Paz de Osnabrück y Münster conocidos como la paz de Westfalia, y que había generado un traslado de importantes recursos de capital a la conformación del Estado y la economía de guerra. Al finalizar las guerras napoleónicas y el imperio británico adentrarse en su pax británica de casi 100 años, esos recursos destinados anteriormente a la guerra, estarían en el mercado financiero en disposición de ser empréstitos para iniciar procesos productivos; no solamente los británicos, sino también de aquellos países que veían en la City de Londres el lugar adecuado para sus inversiones.

Tabla 3.1

Mavores Receptores de Capital Británico, 1865-1914

$(\%)$

\begin{tabular}{|c|c|c|}
\hline Ranking & País & Participación \\
\hline 1 & Estados Unidos & 20.5 \\
\hline 2 & Canadá & 10,1 \\
\hline 3 & Argent ina & 8.6 \\
\hline 4 & Aus tralia & 8,3 \\
\hline 5 & India & 7.8 \\
\hline 6 & África del Sur y otros territorios & 6,4 \\
\hline 7 & Brasil & 4.2 \\
\hline 8 & Rusia & 3,4 \\
\hline 9 & Nueva Zelanda & 2,1 \\
\hline 10 & México & 2,0 \\
\hline 11 & Japón & 1.9 \\
\hline 12 & China & 1,8 \\
\hline 13 & Egipto & 1.6 \\
\hline 14 & Chile & 1,5 \\
\hline 15 & Francia & 1.4 \\
\hline 16 & Rhodesia & 1,1 \\
\hline 17 & Turquía & 1.0 \\
\hline 18 & Italia & 1,0 \\
\hline 19 & Austria-Hungría & 1.0 \\
\hline \multirow[t]{2}{*}{20} & Perú & 0,9 \\
\hline & Total & 86.6 \\
\hline
\end{tabular}

Fuente: Stone (1999) p. 411 
Esto también se consolida con la indemnización de guerra por parte de Francia, establecida en el Tratado de Paris al finalizar la batalla de Waterloo en Noviembre de 1815, que permitió a los banqueros británicos interactuar en el proceso de financiación de Francia y en vincular a los inversionistas en nuevos títulos valores, iniciando un boom importante en la financiación internacional, pieza fundamental en el apetito de los inversionistas por encontrar vehículos de inversión lo suficientemente atractivos y rentables, que el portafolio de productos con que contaba su mercado local hasta ese momento no generaba y, aun más con los procesos especulativos que se vivía con los excedentes de liquidez. Gran Bretaña no tiene que estar a nadie mas agradecido que a ese rufián (Napoleón). Pues gracias a los sucesos provocados por él, la grandeza, prosperidad y riqueza de Inglaterra se han elevado a gran altura. Ella es dueña del mar y, ni en este dominio ni en el comercio mundial, tiene un solo rival a quien temer ${ }^{28}$.

Así mismo, y como lo menciona Michael Petis, el intercambio de deuda del Gobierno británico, permitió absorber nuevos recursos de financiación, pero mas allá de eso fue la vinculación de nuevos inversionistas atraídos por la necesidad de reinvertir sus ganancias en otros instrumentos financieros; que posteriormente se convertirían en la puerta para iniciar la financiación e inversión en diversos lugares con importantes atractivos de rentabilidad, más que de países con simples buenas perspectivas económicas.

Finalmente, y algo que fortalece el avance financiero de los británicos es la posibilidad que da el Parlamento en 1822, de emitir moneda a sus bancos provinciales. Esta será la pieza fundamental para que esas nuevas emisiones de moneda se trasladen a los mercados de crédito y financiación, como parte importante de un aumento de la liquidez; que finalmente conduciría al inicio de un proceso de financiación internacional que permitiría a las inexpertas naciones a adquirir de una forma sencilla pero costosa recursos frescos para la consolidación de sus naciones.

De esta forma encontramos una diversificación de las inversiones británicas alrededor del mundo, no solamente en sus colonias o ex colonias, sino en países donde podría encontrar esa mayor rentabilidad para sus inversionistas y para el abastecimiento de recursos naturales vitales para su avance hegemónico y comercial, que lo mantuvieran como un poder global de primer orden, sin embargo con su estrategia de mantener una baja participación en la inversión directa ${ }^{29}$. Es así, como durante la segunda mitad del siglo XIX, los destinos de inversión británica eran tan distantes y diversos, que podrían estar desde Australia y Nueva Zelanda, pasando por el Imperio Ruso, el Imperio Otomano, el Imperio Austro-Húngaro, Prusia (Alemania), Francia, Sudáfrica, los antiguos territorios de Rhodesia, Brasil, Argentina, Canadá y los Estados Unidos. Durante el periodo de 1865 a 1914, Brasil se convirtió en el séptimo receptor de la inversión británica (Ver Tabla 3.1); teniendo presente que Brasil en esta tercera oleada de financiación iniciada en 1864 se mantendría como un destino estratégico, así como lo había sido en la oleada de 1822 y $1834^{30}$.

\footnotetext{
${ }^{28}$ Comentario del General Prusiano Gneisenau, citado en Kennedy ( 1987) p.233

${ }^{29}$ Wilkins (1988) p. 260

${ }^{30}$ Suter (1992) p.11
} 
Brasil, aunque no fue el primero en iniciar su proceso de financiación con los británicos si se convertiría en un lugar reconocido en la economía mundial del momento por su gran cantidad de recursos, en especial recursos minerales y materias primas ${ }^{31}$. A partir del primer boom de crédito global, Brasil entraría a contratar empréstitos con los bancos británicos como reciprocidad al apoyo que había recibido por parte del Imperio en su proclamación de independencia. Ese apoyo a la creación de una nueva nación brasileña, seria la pieza fundamental para estrechar los vínculos económicos y la influencia política en el avance de Brasil. Aunque es importante resaltar que el aumento de la liquidez y de la economía británica no sólo se consolidó en América, sino en cualquier lugar donde existiera un importante retorno de inversión, incluyendo a sus colonias; los recursos trasladados a Brasil no fueron esenciales para la economía británica, como las inversiones en Canadá, Estados Unidos, Argentina, Australia o India, pero sí importantes; así como lo fueron para la evolución de la economía brasileña.

Sin embargo, era una forma de consolidar un proceso económico sin los altos costos que significaron las colonias durante el siglo XIX, que como lo menciona J.A. Hobson, el imperio británico fue un mal negocio, que obedeció más a la subordinación de los intereses económicos nacionales a un grupo de empresarios privados que usurpan el control de los recursos nacionales y los utilizan para su beneficio personal ${ }^{32}$. Algo similar ocurrió en Brasil, donde la política exterior británica influyó para que el gobierno de Brasil accediera y beneficiara a los empresarios y banqueros británicos en sus intenciones de avanzar en el desarrollo de negocios, posiblemente al punto de ser impositivo en algunos casos.

Tabla 3.2

INVERSION BRITANICA EN BRASIL 1825-1913 En millones de Libras Esterlinas

\begin{tabular}{|c|c|c|c|c|c|c|}
\hline \multirow{3}{*}{$\begin{array}{l}\text { Año } \\
1825\end{array}$} & \multirow{2}{*}{\multicolumn{2}{|c|}{$\begin{array}{l}\text { Inversión } \\
\text { Directa }\end{array}$}} & \multicolumn{3}{|c|}{ Inversión de Portafolio } & \multirow[b]{2}{*}{ Total } \\
\hline & & & \multicolumn{2}{|c|}{$\begin{array}{c}\text { Crédito } \\
\text { Soberano }\end{array}$} & $\begin{array}{c}\text { Crédito } \\
\text { Corporativo }\end{array}$ & \\
\hline & $£$ & 1,0 & $£$ & 3,0 & & 4,0 \\
\hline 1840 & $£$ & 1.7 & $£$ & 5.2 & & 6.9 \\
\hline 1865 & $£$ & 7,2 & $£$ & 13,0 & & $£ \quad 20,3$ \\
\hline 1875 & $£$ & 10,6 & $£$ & 20,4 & & $£ \quad 30,9$ \\
\hline 1885 & $£$ & 22,4 & $£$ & 23,2 & 2,0 & 47,6 \\
\hline 1895 & $£$ & 24,0 & $£$ & 52,4 & 16,6 & 93,0 \\
\hline 1905 & $£$ & 29,6 & $£$ & 83,3 & 11,5 & $£ 124,4$ \\
\hline 1913 & $£$ & 56,7 & $£$ & 119,6 & 78,5 & $£ 254,8$ \\
\hline
\end{tabular}

Fuente: Stone(1977)

\footnotetext{
${ }^{31}$ Ferreira de Souza (2000) p. 24

32 Hobson (1902) p.65

LA RECONFIGURACIÓN BRASILERA YEL IMPERIO BRITÁNICO, 1822-1914. ¿DEPENDENCIA O ESTRATEGIA?
} 
El capital financiero es el generador de los avances económicos y una pieza importante para lograrlo, es su influencia en los procesos políticos no solamente de Inglaterra, sino también de los países como Brasil receptores de su inversión. A partir de este elemento, se determina cómo se han configurado los procesos de inversión británica en Brasil, que a pesar de las diferentes situaciones de especulación y de adversidad al riesgo de préstamos internacionales durante varios momentos del siglo XIX, mantuvo una evolución constante hasta la culminación del periodo de análisis (Tabla 3.2); solamente superado por Argentina al finalizar el siglo XIX y lógicamente por Estados Unidos que gozaba de una dinámica diferente a los países suramericanos; ya se empezaba a configurar después de la guerra de secesión en el nuevo centro económico del mundo, gracias no solamente a sus recursos naturales, a su actividad productiva, sino también al importante traslado de factores de producción británicos. Cuando comenzó la lucha por la supremacía mundial, la economía doméstica estadounidense se hallaba en condiciones de convertirse en el nuevo centro de la economíamundo: un centro conectado con el resto de la economía mundo no tanto mediante flujos comerciales, sino mediante transferencias más o menos unilaterales de fuerza de trabajo, capital y recursos empresariales, que fluían del resto del mundo a su jurisdicción política ${ }^{33}$.

Un punto vital para que Brasil se mantuviera vinculado permanente al mercado de capitales internacional, fue su capacidad de pago generado por su actividad productiva y por la cercanía diplomática con el Imperio Británico, a diferencia de otros países que no contaron con el soporte de su actividad económica, no solamente por su naciente estructura nacional sino también por el desborde de sus pretensiones económicas, que condujeron al impago de su deuda en repetidas ocasiones, como es el caso de México, Argentina, Chile y Perú, entre otros. Así mismo por la intención de los británicos de consolidar cualquier proceso económico que generara dividendos, así fueran de forma coyuntural, creando instituciones comerciales y bancarias temporales, como son los casos de The London and Brazilian Bank, The English Bank of Rio de Janeiro y The London and River Plate Bank, que con la crisis financiera de finales del siglo XIX generaría varias dificultades en la posibilidad de mantenerse como instituciones financieras en el agitado e inestable mercado local.

Muchas de las entidades bancarias establecidas localmente o los grandes prestamistas localizados en la City de Londres, lograron configurar una estructura de financiación a través de los mismos depósitos que mantenían las empresas o el gobierno brasilero en sus entidades, o a través de mecanismos de letras de cambio y pagares que respaldaran su crédito o su obligación. Así mismo, la empresa se convertía en garante de la obligación, y habitualmente no era una empresa de patrimonio exclusivamente local, sino que contaba con participación extranjera que permitía gestionar los avances de la misma; algo normal en los sistemas financieros modernos.

Un elemento importante, que superó en ocasiones el mismo interés por los recursos naturales y materias primas, fue la rentabilidad de los instrumentos financieros y bonos que financiaban las obras de infraestructura y al gobierno brasileño. En ese momento existe una desvinculación de la

${ }^{33}$ Arrighi (1999) p.80 
explotación y comercialización exclusiva de materias primas, la cual seguía, y se centra en el rentable proceso de financiación de ferrocarriles, negocio estratégico de los británicos ${ }^{34}$, y servicios públicos que ya eran demandados por la población brasilera, la más grande de esta zona del continente (Ver Tabla 3.3).

Esta es una razón para que Brasil se mantuviera como lugar importante de las inversiones británicas, y es en ese lugar donde el Imperio logró interactuar en la configuración política de los procesos económicos, pero no entrando a definir los procesos políticos. Era disfrutar de una cercanía política pero sin involucrarse, como si lo había hecho en los primeros años de la instauración de la independencia. En ocasiones la exportación de capital hacia Suramérica fue superada por el avance de Argentina, pero revisando los rendimientos de las inversiones extranjeras en bonos gubernamentales, Brasil superó a Argentina durante todo el periodo 1860-1914, iniciado con el aumento de interés por las bondades económicas de las tierras argentinas en 1860; excepto en 1898 cuando Brasil se encontró con la primera crisis que podría resultar en una cesación de pagos, la cual fue generada por la inestabilidad de la región que se vivía desde 1890, con dos situaciones: la instauración de la República en Brasil y el contagio de la crisis financiera argentina, que se inicio con la cesación de pagos de su deuda y la crisis del Banco Barings por su alta exposición en Argentina ${ }^{35}$.

Tabla 3.3

INVERSION BRITANICA POR SECTORES PRODUCTIVOS

En millones de Libras Esterlinas

\begin{tabular}{|c|c|c|c|c|c|c|c|c|c|c|c|c|}
\hline Sector & \multicolumn{2}{|c|}{1865} & \multicolumn{2}{|c|}{1875} & \multicolumn{2}{|c|}{1885} & \multicolumn{2}{|c|}{1895} & \multicolumn{2}{|c|}{1905} & \multicolumn{2}{|c|}{1913} \\
\hline Ferrocarriles & $£$ & 5,4 & $£$ & 6,4 & $£$ & 17,1 & $£$ & 33,1 & $£$ & 24,0 & & 59,1 \\
\hline Servicios Públicos & $£$ & 0,8 & $£$ & 2,8 & $£$ & 3,1 & $£$ & 3,3 & $£$ & 6,6 & $£$ & 55,0 \\
\hline Bienes Raíces & $£$ & - & $£$ & - & $£$ & - & $£$ & - & $£$ & 0,2 & $£$ & 5,0 \\
\hline Fiducias Financieras & $£$ & - & $£$ & - & $£$ & - & $£$ & - & $£$ & 1,5 & $£$ & 4,2 \\
\hline Café y Caucho & $£$ & - & $£$ & - & $£$ & - & $£$ & - & $£$ & 1,6 & $£$ & 2,2 \\
\hline Minería, Nitrato y Petróleo & $£$ & 0,6 & $£$ & 0,4 & $£$ & 0,9 & $£$ & 1,0 & $£$ & 2,0 & $£$ & 1,5 \\
\hline Hierro, Carbón y Acero & $£$ & - & $£$ & 0,1 & $£$ & 0,1 & $£$ & - & $£$ & - & $£$ & 0,1 \\
\hline Compañías comerciales e Industriales & $£$ & 0,5 & $£$ & 0,9 & $£$ & 3,3 & $£$ & 3,1 & $£$ & 3,6 & $£$ & 8,0 \\
\hline Residual & $£$ & - & $£$ & - & $£$ & - & $£$ & - & $£$ & 1,6 & $£$ & - \\
\hline TOTAL & $£$ & 7,3 & $£$ & 10,6 & $£$ & 24,5 & $£$ & 40,5 & $£$ & 41,1 & & 135,1 \\
\hline
\end{tabular}

Fuente: Stone (1987)

Los rendimientos de los bonos gubernamentales, en promedio durante el periodo 1870-1880, tenia cupones de pago de intereses de 5.6\% para Brasil y 7,0\% para Argentina, pero el rendimiento en el valor del capital era de $0,6 \%$ para Brasil y de $-0,4 \%$ para Argentina. Siendo Brasil el rendimiento

\footnotetext{
${ }^{34}$ Pollard (1985) p.490

${ }^{35}$ Para un análisis económico y econométrico de esta crisis, ver Triner (2001)

LA RECONFIGURACIÓN BRASILERA YELIMPERIO BRITÁNICO, 1822-1914. ¿DEPENDENCIA O ESTRATEGIA?
} 
mas importante de los países de Latinoamérica, y muy lejos de los rendimientos en el valor del capital de otros países: $-9.3 \%$ para Perú, de $-1.0 \%$ para Chile, de $-5.0 \%$ para México y para otros países de Suramérica de $-6.0 \%$ en promedio. E irónicamente ya en ese momento los rendimientos más interesantes se daban en Europa y Estados Unidos ${ }^{36}$.

El capital británico sí configuro el avance de Brasil como Nación, ya que no solamente se volvió un destino comercial, sino que gracias a los incrementos en la liquidez global logró el acceso a recursos financieros que le permitieron fortalecer su economía, su infraestructura, su gobierno y su vinculación al comercio global. No es parte de este documento verificar el avance del desarrollo económico, que posiblemente no se forjó por el capital británico, pero si logró establecer el avance económico de una Nación.

\section{CONCLUSIONES}

La participación británica en la configuración brasileña se dio de una forma contundente durante la época imperial, sin embargo, en la época republicana previa al inicio de la Primera Guerra Mundial, los británicos empezaron a retroceder en su participación e injerencia económica y mucho más política. Esto puede darse por dos razones: un cambio de sistema político que alejó las relaciones económicas entre dos imperios, o un avance económico de países como Estados Unidos y Alemania en los últimos años del periodo imperial de Brasil.

Así mismo, las diversas situaciones de impago generadas durante el siglo XIX, generaron en los inversionistas la búsqueda de destinos más prósperos y estables; una relación costo-beneficio que los Estados Unidos lograron mantener durante todo el siglo XIX, para posteriormente convertirse en destino obligado de las inversiones y por ende de los factores de producción europeo. Dejando a los países de Suramérica como opciones más arriesgadas de inversión y puntales para procesos coyunturales.

Brasil a pesar de su desplazamiento económico generado por el mayor interés en Argentina por parte de los inversionistas británicos y en general europeos, logró mantener una dinámica económica propia, sin entrar en procesos que generaran choques especulativos, económicos o en cesación en los pagos de su deuda. Aunque su buena relación política y económica con los británicos durante el Imperio, le permitió reconfigurar las situaciones adversas que se presentaron en su economía durante el período de análisis; su estructura económica a pesar de sus dificultades y en ocasiones el deterioro en el valor económico, logró respaldar su avance.

Las bonanzas exportadoras en Brasil, no lograrán mantenerse con procesos de reinversión o diversificación, ya que atendían necesidades puntuales y beneficiaban exclusivamente a los

\footnotetext{
${ }^{36}$ Caircross (1935) p.73
} 
terratenientes y los inversionistas. No existió un traslado económico a la población, lo que generó inconformidad en ella y constituiría el inicio de problemas sociales de consideración, para el siglo XX.

El gobierno logró consolidar un proceso burocrático que le permitía avanzar en diferentes aspectos y no solamente el económico, su estructura militar y su estructura política se forjó, no solamente por los ideales políticos y diplomáticos, sino por un proceso de financiación que logró la creación, fortalecimiento y mantenimiento de las instituciones, que serian pieza fundamental para avanzar en su interacción local y en el entorno regional e internacional. Esa financiación fue un monopolio de los británicos hasta el inicio del siglo XX, cuando los franceses iniciaron la financiación del gobierno central brasilero.

Es clara la relación británico - brasilera, debido a que generó una reciprocidad para las dos partes. Los británicos, con un beneficio para su economía, pues los abasteció de materias primas y a sus negocios comerciales y a sus entidades financieras les permitió un proceso de acumulación de capital, porque lograron diversificar y generar rendimientos a su capital financiero, sin enfrentarse a una cesación de pagos, algo frecuente en Latinoamérica durante el periodo, así como encontrarle otro importante destino a su capacidad imperial y futuro socio político y diplomático.

Para los brasileros lograron fortalecer su Nación en los procesos políticos tempranos de su independencia de Portugal; el apoyo británico fue vital para ese avance. Así mismo, se beneficiaron de su cercanía para lograr la obtención de recursos financieros sin una imposición de tarifas y primas de riesgo tan alta como lo vivieron otros países de la región ${ }^{37}$ y avanzar en su consolidación económica. Finalmente lograron configurar un territorio gracias a las excelentes relaciones y su estructura diplomática que habían forjado con la financiación de su burocracia, dejando que los recursos económicos que se lograron con la acumulación de capital de los procesos productivos se destinaran a su avance como Estado y no al desgaste de la guerra; permitiendo una consolidación regional de su diplomacia, su capacidad política y posteriormente de su estructura económica.

La relación de Brasil y el Imperio Británico no fue una relación de dependencia brasilera o de estrategia británica, fue una relación de dependencia estratégica de las dos naciones sustentada sobre la diplomacia económica que culminaría con la Primera guerra mundial y, como lo menciona Niall Ferguson los imperios tienen fecha de expiración ${ }^{38}$, la expiración del Imperio Británico ya se encontraba cerca y la llegada de un nuevo imperio se iniciaba: Estados Unidos.

\footnotetext{
${ }^{37}$ Aunque existe la hipótesis de que las colonias del Imperio Británico gozaron de mejores tasas de interés que los demás países de la periferia. Ver Ferguson y Schularick (2006) p.289

${ }^{38}$ Ferguson (2006) p. 46

LA RECONFIGURACIÓN BRASILERAY EL IMPERIO BRITÁNICO, 1822-1914. ¿DEPENDENCIA O ESTRATEGIA?
} 


\section{BIBLIOGRAFÍA}

Abreu, M. de P. (2005) British business in Brazil: maturity and demise, 1850-1950. Rio de Janeiro: Catholic University of Rio de Janeiro.

Arrighi, G. (1999) El largo Siglo XX. Dinero y Poder en los orígenes de nuestra época. Madrid, edición en español por Ediciones Akal.

Battilossi, S. (2005) «The determinants of multinational banking during the first globalization, 1870-1914». En: Universidad Carlos III de Madrid Working Papers, 05-68. Madrid.

Cain, P.J. and Hopkins, A.G. (1980) «The political economy of British expansion overseas, 1750-1914». The Economic History Review, Vol. 33, No. 4, pp. 463-490.

Caircross, A.K. (1935) «Did foreign investment pay?» The review of economic studies, Vol. 3, No. 1, pp. 67-78.

Calmon, P. (1939) Historia social do Brasil: A época republicana. São Paulo: Companhia editora nacional.

Dean, W. (2000) La economía brasileña 1870-1930. En: Leslie Bethell (editor) Historia de América Latina, Vol. 10: América del Sur 1870-1930. Barcelona: Editorial Critica. pp. 333-369.

De Azevedo, F. (1944) A Cultura Brasileira. São Paulo: Companhia editora nacional.

Fausto, B. (2000) Brasil: Estructura social y política de la primera república 1889-1930. En: Leslie Bethell (editor) Historia de América Latina, Volumen 10: América del Sur 1870-1930. Barcelona: Editorial Critica. pp. 414-455.

Ferguson, N. (2006) «Empires with expiration dates». Foreign Policy, No.156, pp. 46-52.

Ferguson, N. and Schularick, M. (2006) «The Empire Effect: The Determinants of Country Risk in the First Age of Globalization, 1880-1913». The Journal of Economic History, Vol. 66, No.2, pp. 283-312.

Ferreira de Souza, T. (2000) Investimentos Britânicos na mineração brasileira do século XIX: conceito e estratégia do capital. Belo Horizonte: PUC Minas.

Forbes, I. (1978) «German informal Imperialism in South America before 1914». The Economic History Review, Vol. 31, No. 3, pp.384-398.

Graham, R. (1968) Britain and the Onset of modernization in Brazil, 1850-1914. London: Cambridge University Press.

Goes, S. (1991) Navegantes, bandeirantes, diplomatas. Brasília: Fundação Alexandre de Gusmão, Instituto de Pesquisa de Relações internacionais.

Hobson, J.A. (1902) Imperialism: A study. Londres: George Allen \& Unwin.

Iglesias, F. (1994) Breve historia contemporánea del Brasil. México: Fondo de cultura económica. 
Kennedy, P. (1987) Auge y caída de las grandes potencias. Barcelona, edición en español por Plaza \& Janes editores.

Kissinger, H. (1995) La Diplomacia. México, Edición en español por Fondo de cultura Económica.

Leff, N. (1972) «Economic retardation in nineteenth century Brazil» The Economic History review, Vol.25, No. 3, pp.489-507.

Mishkin, F. (2005) «ls financial globalization beneficial?», en: NBER Working paper series, 11891, Cambridge

Pereira de Araújo, J.; Azambuja, M. y Ricupero, R. (1989) Três ensaios sobre diplomacia brasileira. Brasília: Ministério de Relações Exteriores.

Pettis, M. (2003) La máquina de la volatilidad. México, D.F., edición en español por Editorial Océano de México.

Platt, D. C. M. (1980) «British Portfolio Investment Overseas before 1870: Some Doubts». The Economic History Review, Vol. 33, No. 1, pp. 1-16

Pollard, S. (1985) «Capital Exports, 1870-1914: Harmful or Beneficial?» The Economic History Review, Vol. 38, No. 4, pp. 489-514.

Ribeiro, D. (1995) El pueblo brasileño. La formación y el sentido de Brasil. México, D.F.: Fondo de Cultura económica. Primera edición en español 1999.

Schama, S (2002) Auge y caída del imperio Británico, 1776-2000. Barcelona, edición en español por Editorial Critica.

Skidmore, T. y Smith, P. (2001) Modern Latin America. New York: Oxford University Press.

Stone, I. (1999) The global export of capital of Great Britain, 1865-1914: A statistical survey. New York: McMillan Press.

Stone, I. (1987) The composition and distribution of British investment in Latin America, 1865-1913. New York: McMillan Press.

Stone, I. (1977) «British direct and portfolio investment in Latin America before 1914». The Journal of Economic History, Vol. 37, No. 3, pp. 690-722.

Triner, G. (2001) International capital and the Brazilian encilhamento, 1889-1891. An early example of contagion among emerging capital markets? New Jersey: Rutgers University, Department of History.

Wilkins, M. (1988) «The Free-Standing Company, 1870-1914: An Important Type of British Foreign Direct Investment». The Economic History Review, Vol. 41, No. 2, pp. 259-282. 